\title{
Oligonucleotide Array-based Comparative Genomic Hybridization
}

National Cancer Institute

\section{Source}

National Cancer Institute. Oligonucleotide Array-based Comparative Genomic

Hybridization. NCI Thesaurus. Code C116156.

A molecular cytogenetic method combining chromosomal comparative genomic hybridization technique and microarray to detect chromosomal aberrations and changes in DNA copy numbers in the genome, using oligonucleotides immobilized on a solid support as targets for hybridization. 